\title{
The effect of occupational farming on lung function development in young adults: A 15 year follow-up study
}

\section{(C) BMJ Publishing Group Ltd 2015}

Bolund ACS, Miller MR, Basinas I, Elholm G, Omland Ø, Sigsgaard T, Schlünssen V. The effect of occupational farming on lung function development in young adults: a 15-year follow-up study. Occup Environ Med. 2015;72(10):707-13.

Author of correspondence:

MD Anneli Clea Skjelmose Bolund,

Department of Public Health, Section of Environment Occupation \& Health, Danish Ramazzini Centre, University of Aarhus, Bartholins Allé 2, DK-8000 Aarhus C, Denmark

abol@ph.au.dk ～Tel.:+4587168019＜noBreak> Mobile: +452125 $\quad$ T4 47

Anneli C S Bolund ${ }^{\mathrm{a}}$, Martin R Miller ${ }^{\mathrm{b}}$, Ioannis Basinas ${ }^{\mathrm{a}}$, Grethe Elholm ${ }^{\mathrm{a}}$, Øyvind Omland ${ }^{\mathrm{c}}$, Torben Sigsgaard $^{\mathrm{a}}$ and Vivi Schlünssen ${ }^{\mathrm{a}}$.

${ }^{a}$ Department of Public Health, Section of Environment Occupation and Health, Danish Ramazzini Centre, University of Aarhus, 8000 Aarhus C, Denmark.

${ }^{\mathrm{b}}$ Institute of Occupational and Environmental Medicine, University of Birmingham, UK.

${ }^{\mathrm{c}}$ Department of Occupational Medicine, Danish Ramazzini Centre, Aalborg University Hospital, 9100 Aalborg, Denmark.

\section{Keywords:}

Lung function, farming, occupational exposure, organic dust, epidemiology, young adults.

Word counts: $\quad$ Abstract $=250 \quad$ Text $=3732 \quad$ References: 29 
- Organic dust exposure in farming has been shown to have a negative effect on lung function among older adults, especially among pig and dairy farmers.

- The effect on the lungs of young adult farmers may be different as their lungs have not yet fully developed, but only few longitudinal studies have looked at this.

- We found no differences in lung function $\Delta$ z-scores between farmers and controls; however being a current farmer was associated with a negative effect on lung function compared to ex-farmers with females being more susceptible.

- Smoking was associated with a negative effect on lung function and being raised on a farm was protective against the adverse effect of BHR on change in lung function.

- Preventive measures to reduce occupational exposures from farming should include those of a young age and advice against smoking should be given at every opportunity. 


\section{ABSTRACT}

Objectives: Longitudinal studies on the effect of farming on lung function in young subjects are few. Our objective was to explore if farming exposure impaired lung function in young adults.

Methods: We studied 1,964 farming students and 407 controls in 1992/4, and did follow-up in 2007/8. Spirometry, skin prick test, bronchial hyper responsiveness (BHR), height, and weight were measured, and questionnaires covering health and occupation collected. Cumulative dust and endotoxin exposures were estimated from modelled personal dust measurements. Lung function effect was expressed as change in zscore during follow-up using GLI-2012 prediction equations. Longitudinal data were available for 1134 young subjects $\leq 25$ years at baseline.

Results: We found no differences in lung function $\Delta z$-scores between farmers and controls, however, adjusted multivariable linear regression showed a negative effect among current farmers on $\Delta \mathrm{zFEV} 1(-0.12$, $\mathrm{p}=0.006)$ and $\Delta \mathrm{zFEV} 1 / \mathrm{FVC}(-0.15, \mathrm{p}=0.009)$ compared to ex-farmers. An interaction was found between sex and farming, showing that current farming suppresses $\triangle \mathrm{zFEV} 1$ and $\triangle \mathrm{zFVC}$ more among females. Smoking in farmers had a deleterious effect on $\triangle \mathrm{zFEV} 1$ which was not seen in controls, though no significant interaction was found. Farm upbringing protected against impairment of lung function, and BHR at baseline had a deleterious effect on $\triangle \mathrm{zFEV} 1$ only in those not raised on a farm.

Conclusion: We conclude that being a current farmer is associated with a negative effect on lung function compared to ex-farmers, with females being more susceptible. Being raised on a farm protects against the adverse effect of BHR on change in lung function. 


\section{INTRODUCTION}

Organic dust exposure in farming has a negative effect on lung function, especially among pig and dairy farmers [1-5]. The effect on the lungs of young adult farmers may be different as their lungs have not yet fully developed. Lung function increases continuously until the mid-20s, and then plateaus before starting to decline from about 30-35 years of age [6]. To compare a subject's lung function against reference equations from late teens to adulthood has previously been difficult because of the need to use separate equations for subjects up to their late teens and for adults from 18 years onwards. Recently, the Lambda-Mu-Sigma equations (LMS) [7] from the Global Lung Initiative project (GLI-2012) [8] have become available. With one set of equations they cover lung function from the age of 3 to 95 years in the general population. This permits lung function comparisons in population terms (as z-scores), making it possible to assess lung function changes in young adults in a consistent way without using discordant equations.

Prospective studies of the specific effect of farming exposure on lung function among young adults have been few and sparse in terms of population size and time of follow-up. Prior et al. [9] showed a slight overall decrease in FVC over a 4 year follow-up period in a group of 42 young farmers. A larger population based study showed that after 9 years of follow-up young individuals exposed to dusts, gases, and fumes in different occupations (including farming) did not have a steeper overall decline in lung function than individuals without occupational exposure [10]. We have applied the data from the large Danish SUS cohort

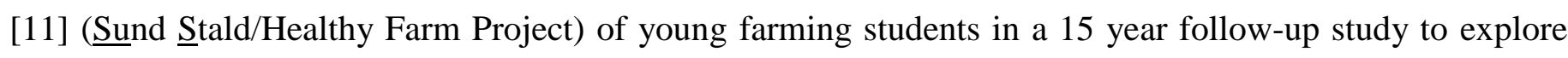
the effect of farming exposure on lung function at young age.

\section{METHODS}

\section{Study population}

The SUS cohort was established in 1992 with the intention to study the health effects of farming exposure. The original cross-sectional study consisted of 2478 farming students identified during their second stay at the farming schools in Denmark during the period February 1992 to February 1994. Of 2004 students (81\%) who indicated that they wished to participate, 40 (2\%) did not attend for their baseline clinical assessment. The final group consisted of 1734 male and 230 female farming students. Male army draftees examined prior to decision of recruitment were invited to participate as controls, provided that they came from rural areas and with no intention of becoming farmers. There were 967 eligible army draftees of whom 592 (61\%) agreed to participate. A random sample of 407 of these male recruits were chosen and used as controls in the study.

The cohort consisted of young adults with a median (interquartile range) age of 18.7 yrs (18.2 - 19.5). In 2007 and 2008 we did a large follow-up of the cohort with a participation of $51.7 \%$ of the 2262 cohort members who could be identified [11]. 
This paper considers the effect of occupational farming exposure on lung function during young adulthood. We therefore excluded all participants above 25 years of age at baseline (male farmers $n=15$, female farmers $\mathrm{n}=11$ ). Additionally ten participants had missing spirometry measurements and were therefore excluded. The follow-up group ( $\mathrm{n}=1134)$ comprised 866 male farmers, 96 female farmers, and 172 male controls (Fig. S1). The SUS study and the SUS follow-up study were both approved by the ethics committee of Aarhus County (AA-19912197 and AA-20070074 respectively) and the Danish Data Protection Agency. Informed written consent was obtained from all participants.

\section{Questionnaires}

Participants answered questionnaires based on the modified British Medical Research Council questionnaire [12] supplemented with questions from the European Community Respiratory Health Survey [13] at followup. The questionnaires dealt with general health issues, respiratory symptoms, asthma, allergy, smoking habits, and occupational history. All participants with occupational farming experience filled in a farmingspecific occupational questionnaire covering the type and level of farming exposure for all employments since age 15.

\section{Measurements}

Lung function was assessed at baseline and follow-up by measuring FEV1, FVC, and FEV1/FVC according to guidelines of the American Thoracic Society/European Respiratory Society (ATS/ERS) [14] using a dry wedge spirometer (S-type spirometer no. 20.600, Vitalograph Ltd, Buckingham, UK) with a maximum volume of 7.7 L. The GLI-2012 equations [8] were applied to calculate the main outcome measures as change in z-scores ( $\Delta$ z-scores) during follow-up for the three lung function indices taking age, height, sex and ethnicity into consideration. The study lacks female controls, however z-scores have been calculated comparing female farmers with women in a reference population (GLI2012), hereby taking sex into account before comparing z-scores between farmers (female and male) and controls (male).

Height was measured at baseline and follow-up and weight at follow-up, from which follow-up BMI was calculated. Bronchial hyper-responsiveness (BHR), expressed as PD20 for FEV1, was assessed with histamine at baseline and methacholine at follow-up using a modified [15] Yan method [16]. Studies have shown that these agents are comparable [17]. At baseline and follow-up skin prick testing was performed as previously described [15]. Positive atopic status was defined as at least one positive reaction of $\geq 3 \mathrm{~mm}$ in mean diameter to any of 9 common aero-allergens [11] provided a negative control.

\section{Exposure assignment}

The cumulative exposures to dust and endotoxin during follow-up were estimated for every participant based on personal exposure measurements ( $n=507$ among 327 farmers) performed in 2008-2009 [18]. Mean 
time-weighted average (TWA, 8-hour) dust and endotoxin concentrations for pig, cattle and field farming were estimated. For every participant the total number of work years in swine, cattle, and field farming, standardised to a 40-hours work week, were calculated from the occupational questionnaires. Cumulative exposures were calculated as the sum of the products of the TWA dust and endotoxin concentrations and the total work years during follow-up for each type of work.

Smoking was expressed as pack-years (equal to 20 cigarettes $\cdot$ day $^{-1} \cdot y r s$ ) during the follow-up period. Participants were divided into never smokers, ex-smokers, and current smokers at follow-up. Smokers who quit smoking less than two years before follow-up were defined as current smokers. Current smokers were split into low (0-10 pack-years) and high (10-59 pack-years) accumulated smoking exposure during the follow-up period.

\section{Data analyses}

Statistical analysis was carried out using STATA 12.1. For normally distributed data, mean \pm SD was reported and for non-normally distributed data, median (min-max or interquartile range) was reported.

Baseline z-scores (zFEV1, zFVC and zFEV1/FVC) and height were normally distributed and comparisons between participants and non-participants were made using Students' t-test. The continuous variables for absolute lung function values and changes in z-scores during follow-up were normally distributed and here comparisons between farmers and controls were made using analysis of variance (ANOVA). Mann-Whitney within group comparison was used to compare changes in z-scores between smokers and nonsmokers. For the categorical variables "Smoker”, "Raised on a farm”, “Asthma”, and "BHR” $\chi^{2}$-tests were used to compare farmers and controls. Spearman correlation coefficients were estimated to examine the relationship between dust and endotoxin exposure.

Possible confounders considered for multivariable linear regression analysis were sex, side-job with high dust exposure, other dust exposures, lung disease, BMI, smoking, farm upbringing, urban upbringing, bronchitis, BHR, atopy, self reported asthma, and second hand smoking (smokers in childhood home). The final models included a priori selected confounders with plausible effect on lung function change. First order interactions between exposures and confounders were explored. The level of significance was set at $\mathrm{p}<0.05$.

\section{RESULTS}

Comparing baseline characteristics of participants and non-participants aged $<25$ years at baseline showed few differences (Table S1). The participation rate at follow-up was 51.7\%. Those failing to participate in the follow-up were more likely to have been smokers at baseline. Participating male farmers were more likely to have been raised on a farm, had less asthma at baseline and had significantly better zFEV1 and zFEV1/FVC at baseline compared to non-participating male farmers. The same tendencies were seen for controls. The demographics and exposure characteristics of the follow-up cohort can be seen in Table 1. 
Table 1 Demographics and exposure characteristics of the cohort.

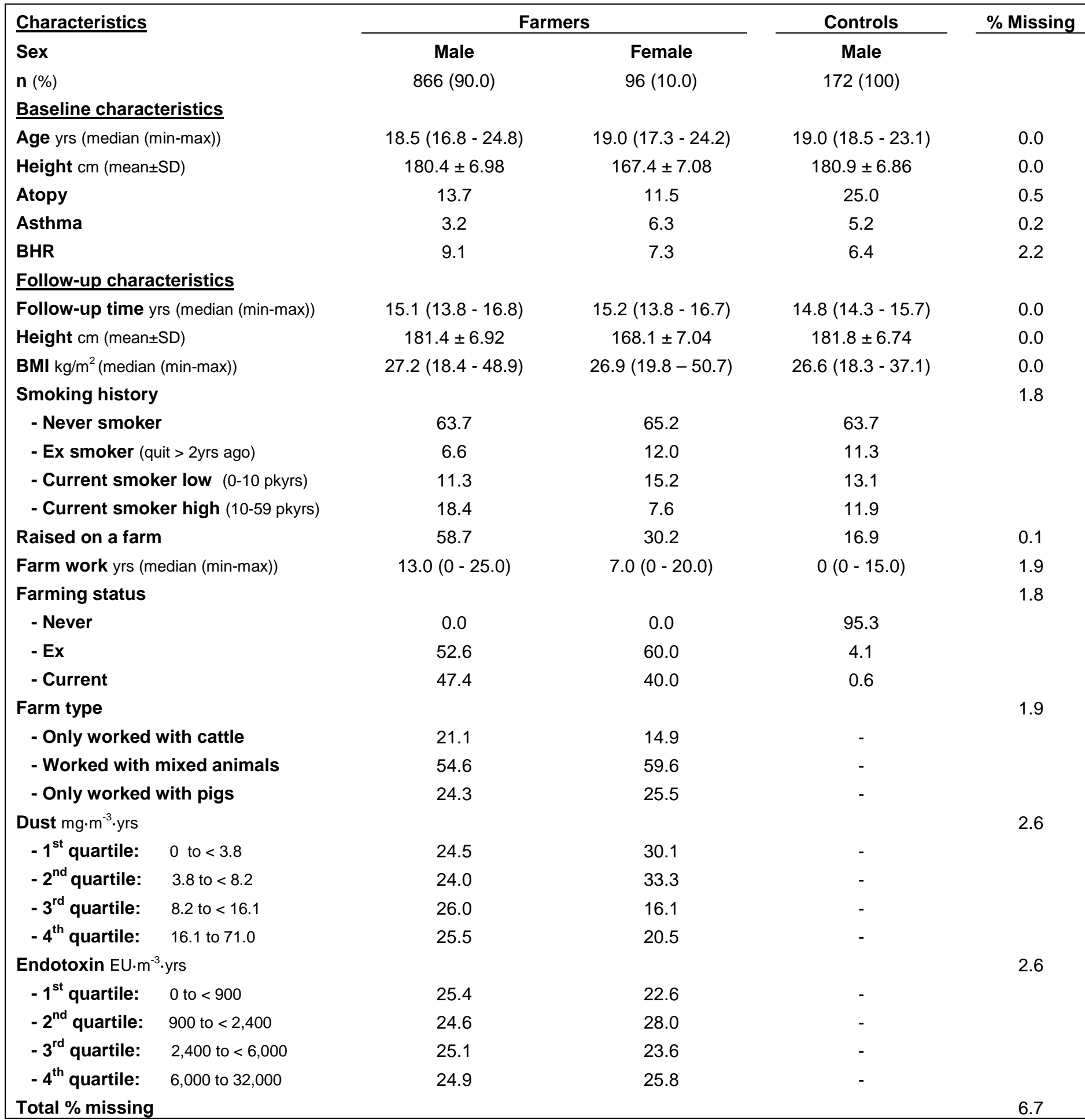

Expressed as \% unless otherwise specified.

The cumulative dust and endotoxin exposures among farmers (male and female) had a median (min-max) of $8.2(0-71) \mathrm{mg} \cdot \mathrm{m}^{-3} \cdot \mathrm{yrs}$ and 2,400 $(0-32,000) \mathrm{EU} \cdot \mathrm{m}^{-3} \cdot \mathrm{yrs}$, respectively. The exposures were divided into quartiles for further analysis. The distribution of male and female farmers in the different quartiles of endotoxin was even, but for dust quartiles the distribution was a bit uneven with more female in the lower quartiles of dust exposure $\left(\mathrm{p}<0.05, \chi^{2}\right.$ test). Dust and endotoxin exposures were strongly correlated 
(correlation between quartiles: Spearman $\rho=0.93$, $\mathrm{p}<0.001$ ). A few controls (8/172) reported a small amount of farming exposure, but were for further analyses still treated as controls. Compared to male controls the proportion of high current smoking was greater and the proportion of ex-smoking was lower among male farmers $\left(\mathrm{p}<0.05, \chi^{2}\right.$ test $)$.

Comparing ex-farmers and current farmers (table S2) showed differences concerning height (current farmers were on average $2 \mathrm{~cm}$ taller at both baseline and follow-up), asthma, which was less prevalent among current farmers at baseline, z-score for FEV1/FVC, which started significantly higher at baseline for current farmers despite zFEV1 and zFVC not being significantly different at baseline between the groups. Also smoking showed differences with current farmers being more likely to be never-smokers and less likely to be current smokers at follow-up compared to ex-farmers. Significantly more current farmers were raised on a farm and had more years of active farm work during follow-up compared to ex-farmers. Similarly current farmers were more likely to be in the higher quartiles of dust and endotoxin exposure than ex-farmers.

The absolute lung function values at baseline and follow-up expressed as mean \pm SD are shown in Table S3 together with baseline z-scores and the change in z-scores during follow-up. The absolute values for FVC increased during follow-up and decreased slightly for FEV1. The baseline z-scores for FEV1 and FVC in male farmers were slightly but non-significantly lower than in controls. For change in z-scores during follow-up, there was no significant difference between farmers and controls. When stratified by smoking status at follow-up there was a significant difference in $\triangle \mathrm{zFEV} 1$ between smokers and non-smokers but only among the farmers (Table 2).

Table 2 Change during follow-up in z-scores for lung function stratified by follow-up smoking status.

\begin{tabular}{|c|c|c|c|c|}
\hline Participants (n) & Smoker (n) & $\Delta z F E V_{1}$ & $\Delta z F V C$ & $\Delta z F E V_{1} / F V C$ \\
\hline \multirow[t]{2}{*}{ Controls (172) } & Yes (44) & $0.16 \pm 0.65$ & $0.37 \pm 0.55$ & $-0.32 \pm 0.82$ \\
\hline & No (128) & $0.23 \pm 0.61$ & $0.44 \pm 0.61$ & $-0.31 \pm 0.82$ \\
\hline \multirow[t]{2}{*}{ Female Farmers (94) } & Yes (23) & $-0.09 \pm 0.54^{*}$ & $0.10 \pm 0.80$ & $-0.27 \pm 1.02$ \\
\hline & No (71) & $0.30 \pm 0.81$ & $0.25 \pm 0.69$ & $0.01 \pm 0.93$ \\
\hline \multirow[t]{2}{*}{ Male Farmers (865) } & Yes (262) & $0.02 \pm 0.66^{\star *}$ & $0.25 \pm 0.68$ & $-0.35 \pm 0.85^{\star \star}$ \\
\hline & No (603) & $0.22 \pm 0.65$ & $0.33 \pm 0.69$ & $-0.16 \pm 0.81$ \\
\hline
\end{tabular}

All values shown as mean \pm SD.

${ }^{*} \mathrm{p} \leq 0.015,{ }^{* *} \mathrm{p} \leq 0.001$ (Mann-Whitney within group comparison between smokers and nonsmokers).

For both female and male farmers the positive change in $\triangle \mathrm{zFEV} 1$ during follow-up was significantly smaller among smokers compared to non-smokers. The $\triangle \mathrm{zFEV1/FVC} \mathrm{during} \mathrm{follow-up} \mathrm{was} \mathrm{more} \mathrm{negative} \mathrm{in} \mathrm{male}$ farmers who smoked compared to non-smokers. There was a similar non-significant trend in the female farmers. Smoking did not affect the controls to the same degree as the farmers. 
Multivariable linear regression analyses to predict change in lung function over the follow up period for farmers compared to controls can be seen in Table 3 . 
Table 3 Estimates of the expected change during follow-up for lung function z-scores per unit change in predictor variables, when comparing farmers to controls. ( $\mathrm{n}=1058)$.

\begin{tabular}{|c|c|c|c|c|c|c|}
\hline \multirow[t]{2}{*}{ Regression model } & \multicolumn{2}{|c|}{$\Delta \mathrm{zFEV} 1\left(\mathrm{R}^{2}=0.13\right)$} & \multicolumn{2}{|c|}{$\Delta \mathbf{z F V C}\left(\mathrm{R}^{2}=0.23\right)$} & \multicolumn{2}{|c|}{$\Delta$ zFEV1/FVC $\left(\mathrm{R}^{2}=0.06\right)$} \\
\hline & $\mathrm{E}(95 \% \mathrm{Cl})$ & p & $\mathrm{E}(95 \% \mathrm{Cl})$ & $\mathbf{p}$ & $\mathrm{E}(95 \% \mathrm{Cl})$ & $\mathbf{p}$ \\
\hline Control & 0 & - & 0 & - & 0 & - \\
\hline Farmer status: Ex & $0.05(-0.07$ to 0.16$)$ & 0.414 & $-0.05(-0.16$ to 0.06$)$ & 0.393 & $0.14(-0.01$ to 0.29$)$ & 0.074 \\
\hline Current & $-0.07(-0.19$ to 0.05$)$ & 0.272 & $-0.09(-0.21$ to 0.03$)$ & 0.139 & $-0.01(-0.17$ to 0.15$)$ & 0.932 \\
\hline Smoking: Ex-smoker & $0.04(-0.10$ to 0.18$)$ & 0.573 & $-0.06(-0.20$ to 0.08$)$ & 0.402 & $0.15(-0.04$ to 0.34$)$ & 0.123 \\
\hline Current low & $-0.11(-0.23$ to 0.01$)$ & 0.081 & $-0.01(-0.12$ to 0.11$)$ & 0.906 & $-0.15(-0.31$ to 0.01$)$ & 0.065 \\
\hline Current high & $-0.24(-0.35$ to -0.14$)$ & 0.000 & $-0.10(-0.21$ to -0.003$)$ & 0.044 & $-0.20(-0.33$ to -0.06$)$ & 0.005 \\
\hline Second hand smoking & $-0.08(-0.16$ to 0.01$)$ & 0.069 & $-0.09(-0.17$ to -0.01$)$ & 0.025 & $0.04(-0.07$ to 0.15$)$ & 0.465 \\
\hline Raised on a farm & $0.10(0.01$ to 0.18$)$ & 0.025 & $0.08(-0.000$ to 0.16$)$ & 0.050 & $0.06(-0.05$ to 0.17$)$ & 0.274 \\
\hline Baseline BHR & $-0.09(-0.22$ to 0.04$)$ & 0.190 & $-0.13(-0.26$ to -0.005$)$ & 0.042 & $0.01(-0.16$ to 0.19$)$ & 0.876 \\
\hline Follow-up BMI & $-0.05(-0.06$ to -0.04$)$ & 0.000 & $-0.07(-0.08$ to -0.06$)$ & 0.000 & $0.03(0.02$ to 0.05$)$ & 0.000 \\
\hline
\end{tabular}


Predictors included in the models were a priori selected based on plausible confounding effects on the change in lung function z-scores. Being a current or an ex-farmer compared to a control was not associated with a significant difference in change in z-score. High current smoking and follow up BMI had a negative effect on both $\triangle \mathrm{zFEV} 1$ and $\Delta \mathrm{zFVC}$ and being raised on a farm mitigated the effect. In order to quantify the absolute impact on lung function, we found that a change of 1 z-score in FEV1 equates to $515.5 \mathrm{~mL}$ for a man aged 25 years with height $175 \mathrm{~cm}$ [8], and for FVC equates to $622.8 \mathrm{~mL}$. From Table 3 the effect of being a high current smoker equates to the FEV1 being $124 \mathrm{~mL}$ (95\% CI, 72-180 mL) lower than a nonsmoking control at the end of follow-up and the FVC being $62 \mathrm{~mL}$ (95\% CI, 2-131 mL) lower. Sensitivity analyses adjusting for smoker/non-smoker at follow up did not change the estimates of effect. Sensitivity analyses excluding the female farmers also showed similar results (data not shown).

Being raised on a farm was associated with a larger positive $\triangle \mathrm{zFEV} 1$ and $\triangle \mathrm{zFVC}$ compared to those not raised on a farm, whereas baseline BHR significantly reduced $\triangle \mathrm{zFVC}$. Looking at BHR-stratified analyses we found that among those without BHR at baseline $(n=965)$ being raised on a farm no longer had a significant effect on $\triangle \mathrm{zFEV} 1$ and $\triangle \mathrm{zFVC}$, but in those with BHR at baseline $(\mathrm{n}=93)$ being raised on a farm was associated with a larger positive $\Delta \mathrm{zFEV} 1(0.39, \mathrm{p}=0.020)$ and $\Delta \mathrm{zFVC}(0.32, \mathrm{p}=0.035)$. This interaction between baseline BHR and being raised on a farm was explored by rerunning the regression with an interaction term. This showed that if you were not raised on a farm having baseline BHR had a negative effect on the $\triangle \mathrm{zFEV} 1$ and $\triangle \mathrm{zFVC}$ compared to those without baseline BHR; however, if you were raised on a farm $\triangle \mathrm{zFEV} 1$ and $\triangle \mathrm{zFVC}$ were not significantly affected irrespective of BHR status. The coefficient for the interaction term was $0.24(\mathrm{p}=0.074)$ in the model for $\Delta \mathrm{zFEV} 1$ and $0.27(\mathrm{p}=0.044)$ in the model for $\triangle \mathrm{zFVC}$. Figure 1a illustrates the separate combinations of baseline BHR (yes/no) and being raised on a farm (yes/no) for FEV1 and FVC for all the study subjects together. Figures $1 \mathrm{~b}$ and 1c illustrate this for FEV1 and FVC respectively with controls and farmers separated. Atopy and BHR were correlated (Spearman $\rho=0.19$, $\mathrm{p}<0.001$ ) and exactly the same interaction was seen between baseline atopy and being raised on a farm. These findings were stronger when controlling for baseline values of zFEV1 and zFVC, arguing that the protective effect of being raised on a farm was not due to preexisting impairment of lung function.

Multivariable linear regression analyses (equivalent to Table 3) stratified by baseline atopy did not change the estimates of effect of farmer status but showed a stronger negative effect of BHR among atopics $(n=158)$ than non-atopics ( $\mathrm{n}=895$ ) especially on $\Delta \mathrm{zFVC}(-0.23, \mathrm{p}=0.05$ vs. $-0.07, \mathrm{p}=0.41$ respectively).

Table 4 presents linear regression analyses of the effect of cumulative farming exposures during follow-up on lung function for farmers only, using the same confounders as in previous analyses (Table 4) and including sex. When farming exposure was assessed by quartiles of dust and endotoxin (analysis A and B) no significant differences were seen among the different quartiles in farmers and change in lung function, 
and the quartiles of exposure in farmers were not associated with change in lung function compared to the controls (data not shown). 
Table 4. Estimates of the expected change during follow-up for lung function z-scores per unit change in exposure variables in separate analytical models including (A) dust exposure, (B) endotoxin exposure, (C) farm type and (D) farm status. (A, B, C for current and ex-farmers together, D comparing current and ex-farmers)

\begin{tabular}{|c|c|c|c|c|c|c|c|c|c|}
\hline \multirow[t]{2}{*}{ Regression models } & \multirow[b]{2}{*}{$\mathbf{R}^{2}$} & \multicolumn{2}{|l|}{$\Delta \mathrm{zFEV1}$} & \multirow[b]{2}{*}{$\mathbf{R}^{2}$} & \multicolumn{2}{|l|}{$\Delta \mathrm{zFVC}$} & \multirow{3}{*}{$\begin{array}{c}\mathbf{R}^{2} \\
0.06\end{array}$} & \multicolumn{2}{|l|}{$\Delta z$ Ratio } \\
\hline & & $\mathrm{E}(95 \% \mathrm{Cl})$ & p & & $\mathrm{E}(95 \% \mathrm{Cl})$ & p & & $\mathrm{E}(95 \% \mathrm{Cl})$ & p \\
\hline A Dust: $(n=892)$ & 0.14 & & & 0.24 & & & & & \\
\hline $1^{\text {st }}$ quartile & & 0 & - & & 0 & - & & 0 & - \\
\hline $2^{\text {nd }}$ quartile & & $-0.06(-0.17$ to 0.06$)$ & 0.359 & & $-0.01(-0.13$ to 0.10$)$ & 0.816 & & $-0.06(-0.21$ to 0.10$)$ & 0.468 \\
\hline $3^{\text {rd }}$ quartile & & $-0.03(-0.15$ to 0.09$)$ & 0.590 & & $-0.04(-0.15$ to 0.08$)$ & 0.529 & & $-0.01(-0.17$ to 0.14$)$ & 0.880 \\
\hline $4^{\text {th }}$ quartile & & $-0.02(-0.14$ to 0.10$)$ & 0.733 & & $0.03(-0.09$ to 0.15$)$ & 0.619 & & $-0.09(-0.25$ to 0.06$)$ & 0.245 \\
\hline B Endotoxin: $(n=892)$ & 0.13 & & & 0.24 & & & 0.06 & & \\
\hline $1^{\text {st }}$ quartile & & 0 & - & & 0 & - & & 0 & - \\
\hline $2^{\text {nd }}$ quartile & & $-0.10(-0.22$ to 0.02$)$ & 0.104 & & $-0.09(-0.21$ to 0.02$)$ & 0.117 & & $-0.01(-0.17$ to 0.14$)$ & 0.865 \\
\hline $3^{\text {rd }}$ quartile & & $-0.07(-0.19$ to 0.05$)$ & 0.233 & & $-0.07(-0.19$ to 0.04$)$ & 0.205 & & $-0.003(-0.16$ to 0.15$)$ & 0.964 \\
\hline $4^{\text {th }}$ quartile & & $-0.03(-0.15$ to 0.09$)$ & 0.662 & & $-0.02(-0.13$ to 0.10$)$ & 0.754 & & $-0.03(-0.18$ to 0.13$)$ & 0.739 \\
\hline C Farm type: (=896) & & & & & & & & & \\
\hline Only cattle & 0.13 & 0 & - & 0.23 & 0 & - & 0.05 & 0 & - \\
\hline Mixed pigs/cattle & & $-0.03(-0.13$ to 0.08$)$ & 0.619 & & $-0.06(-0.16$ to 0.04$)$ & 0.264 & & $0.07(-0.11$ to 0.17$)$ & 0.659 \\
\hline Only pigs & & $-0.02(-0.14$ to 0.11$)$ & 0.786 & & $-0.03(-0.15$ to 0.09 & 0.667 & & $0.00(-0.16$ to 0.17$)$ & 0.955 \\
\hline D Farm status: $(n=897)$ & 0.14 & & & 0.23 & & & 0.06 & & \\
\hline Ex-farmers & & 0 & - & & 0 & - & & 0 & - \\
\hline Current farmers & & $-0.12(-0.21$ to -0.03$)$ & 0.006 & & $-0.04(-0.13$ to 0.04$)$ & 0.334 & & $-0.15(-0.26$ to -0.04$)$ & 0.009 \\
\hline
\end{tabular}

E=Estimate. 95\% CI=95\% Confidence Interval. p=p-value.

Mutually adjusted for smoking, second hand smoking, sex, being raised on a farm, baseline BHR, and follow-up BMI. 
Analyses by type of farming did not show systematic differences between only cattle-, only pig- or mixedfarmers (Table $4(\mathrm{C})$ ), and the type of farming was not associated with change in lung function compared to the controls (data not shown).

Multivariable linear regression analysis comparing only current farmers with ex-farmers (controls excluded) showed a significant worse effect among current farmers on $\Delta \mathrm{zFEV} 1(-0.12, \mathrm{p}=0.006)$ and $\Delta \mathrm{zFEV} 1 / \mathrm{FVC}$ $(-0.15, p=0.009)$ (Table 4 (D)). The total cumulative dust exposure was significantly lower among the exfarmers (mean \pm SD: $6.3 \mathrm{mg} \cdot \mathrm{m}^{-3} \cdot \mathrm{yrs} \pm 6.7$ ) compared to the current farmers $\left(17.5 \mathrm{mg} \cdot \mathrm{m}^{-3} \cdot \mathrm{yrs} \pm 11.4, \mathrm{p}<0.001\right.$ ranksum test) and the same was true for the cumulative endotoxin exposure $\left(2300 \mathrm{EU} \cdot \mathrm{m}^{-3} \cdot \mathrm{yrs} \pm 2900 \mathrm{vs}\right.$. $6500 \mathrm{EU} \cdot \mathrm{m}^{-3} \cdot \mathrm{yrs} \pm 5400, \mathrm{p}<0.001$ ranksum test). However, when assessing only current farmers no exposure-response relationship between change in z-scores and their quartiles of dust and endotoxin exposures was seen and the same was true for ex-farmers and their quartiles of exposures (data not shown).

A significant interaction term between sex and current farming was seen in the model for $\Delta \mathrm{zFVC}(-0.30$, $\mathrm{p}=0.034)$ and a borderline significant interaction term was seen in the model for $\Delta z F E V 1(-0.25, p=0.08)$. This indicates that sex modifies the effect of current farming on change in lung function compared to exfarming with females being more susceptible (references in the model with the interaction term were male ex-farmers).

\section{DISCUSSION}

In this study the longitudinal change in lung function among young farmers did not differ significantly from the lung function change among controls when compared to population reference levels. Being a current farmer compared to an ex-farmer had a larger negative impact on lung function. This might suggest a negative effect of high levels of dust and endotoxin exposures. However, looking at the quartiles of exposure no exposure-response relation was seen, though it may represent a more acute effect on lung function among current farmers.

The lung function change was negatively associated with baseline BHR, smoking and not being raised on a farm. Smoking had a negative effect on $\Delta z F E V 1$ and $\triangle \mathrm{zFEV} 1 / \mathrm{FVC}$ but only among farmers. This finding could suggest the effect of smoking to be modified by farming exposures, though we found no significant interaction between farming exposure and smoking (data not shown). The lack of an effect of smoking in the controls could be that there were too few subjects to detect a true effect. However, smoking prevalence in the 94 female farmers was $24.5 \%$ and lower than in the controls (25.6\%) and yet an effect on $\Delta \mathrm{zFEV} 1$ was seen in the female farming smokers compared to non-smokers (Table S2).

We found a significant interaction between baseline BHR and place of upbringing. This suggests that farm upbringing attenuates the negative effect of BHR on lung function. The protective effect of being raised on a 
farm was not due to preexisting impairment of lung function among those raised on a farm and there were no significant differences in prevalence of BHR between those raised on a farm and those not, neither among farmers nor controls. Terho et al and Schulze et al [19,20] similarly found no difference in BHR prevalence among those raised on a farm and those not. To our knowledge no other study has seen an interaction between BHR and place of upbringing and the effect of this on the development of lung function.

We also found a significant interaction between sex and farming status, showing a negative effect on $\Delta \mathrm{zFV}$ and $\triangle \mathrm{zFEV} 1$ primarily among female current farmers. This could be a reflection of a higher susceptibility in females towards the chronic occupational exposure. We have shown in earlier studies that female workers in the wood industry also seem to be more susceptible to the occupational exposure [21].

We cannot predict when the peak of lung function was reached during follow-up for each individual. Therefore, we do not know if the impaired lung function seen among current farmers compared to exfarmers depicts an actual impaired lung development during follow-up or a deleterious effect from farming exposure on fully developed lungs. But as the absolute values show an increase in FVC during follow-up, we know that some of the participants have been exposed during lung development. To be able to say more about the actual impact on lung development, multiple repeated measurements of lung function during the follow-up period would have been needed.

Assessing the lung function change of young people using the GLI-2012 equations covers the change in one continuous set of prediction equations. We found that z-scores for lung function increased during follow-up in both farmers and controls, confirming that longitudinal lung function change in the young is different from that estimated from cross-sectional lung function prediction equations [22,23], possibly due to cohort effects. One problem that may still be present is that the error between longitudinal and cross-sectional equations might be sex dependent. A limitation of our study is the lack of female controls and this restraint might have affected our results. However, the estimated effects did not change when all women were excluded from the analyses (data not shown).

Adjusting for the baseline level of lung function in regression analyses testing estimates of effect on lung function change is a controversial and highly debated practice because of correlated errors between lung function level and lung function change [24]. The effects of these correlated errors on the regression coefficients may lead to bias due to the "horse-racing effect" $[25,26]$ whereby loss is negatively associated with attained level, i.e. the lower one's function, the more one loses [24]. To avoid over adjustment we did not adjust for baseline z-scores and this choice was supported by a sensitivity analyses including baseline zscores for lung function in the regression models which did not change the estimates of effect (data not shown). 
In our study occupational history was based on self-reported questionnaires introducing possible recall bias concerning the reported details of each employment. In our exposure assessment we included actual personal dust measurements allowing us to calculate individual quantitative cumulated exposure estimates during follow-up. The dust and endotoxin exposure estimates were however strongly correlated. Other nonassessed exposures in the farming environment, such as ammonia, molds, and disinfectants, may be similarly correlated to our measured exposures $[3,27]$. Therefore it is not possible to state the exact elements of the farming exposure that have an effect on the lung function changes over time. We may have underestimated the true total exposures because of possible improvements in the farming environment that were accomplished during course of the follow-up in terms of better ventilation and cleaning systems; but a recent review suggest that no clear downward trend in exposure of livestock farmers is observed during the last 3 decades [28].

The strength of this study is the reliable information on health, smoking habits, working history and specific exposure in a large follow-up cohort of young adults. Thorough lung function testing was performed with good internal consistency and reproducibility [15]. The lung function measurements were assessed the same way at baseline and follow-up by the same small group of assessors. The baseline farming cohort comprised 79\% of all farming students in Denmark during 1992-1994 [29]. A participation rate at follow-up of only $51.7 \%$ may relate to the follow-up examination no longer taking place at the subjects' place of work (as it did at baseline) and that the study subjects were all young with changing personal circumstances. Differences in demographics between participants and non-participants at follow-up were small and we do not expect these to influence the results. We consider our results to be representative for Danish farmers, as well as farmers in temperate zones with similar farming methods.

We found no differences in lung function $\Delta$ z-scores between farmers and controls; however we can conclude that continuing farming exposure in young adults is associated with a negative effect on lung function development when compared to those who quit farming, with this effect being more prominent in females. Being bronchial hyper responsive has a negative effect on longitudinal lung function which is attenuated in those raised on a farm. Already at this young age smoking has a clear deleterious effect on lung function development so preventive measures to reduce occupational exposures from farming should include those of a young age and advice against smoking should be given at every opportunity. 


\section{Acknowledgements}

The authors wish to thank all the farming students and control subjects for their patience and enthusiasm, and all personnel that contributed to this large follow-up study. Results will be communicated to the Danish Agriculture Council and the farm schools where participants were initially included.

\section{Funding}

Main funding contributors for the SUS study were The Danish Lung Association, The Danish Agency for Science Technology and Innovation, The Danish Medical Research Council, The Danish Agricultural Research Council, Helsefonden, The PC Petersen Foundation, The Danish Research Council Aarhus University, and The Danish Working Environment Research Fund. The funding sources had no involvement in decisions made in regards to the study and publications.

\section{Contributorship statement}

Anneli C. S. Bolund, corresponding author, has contributed to 1) conception and design, acquisition of data, analysis and interpretation of data; 2) drafting the article; and 3) final approval of the version to be published.

Martin R. Miller has contributed to 1) analysis and interpretation of data; 2) drafting the article and revising it critically for important intellectual content; and 3) final approval of the version to be published. Ioannis Basinas has contributed to 1) conception and design, acquisition of data; 2) revising the article critically for important intellectual content; and 3) final approval of the version to be published.

Grethe Elholm has contributed to 1) analysis and interpretation of data; 2) revising the article critically for important intellectual content; and 3) final approval of the version to be published.

Øyvind Omland has contributed to 1) conception and design, acquisition of data; 2) revising the article critically for important intellectual content; and 3) final approval of the version to be published.

Torben Sigsgaard has contributed to 1) conception and design, acquisition of data, analysis and interpretation of data; 2) revising the article critically for important intellectual content; and 3) final approval of the version to be published.

Vivi Schlünssen has contributed to 1) conception and design, acquisition of data, analysis and interpretation of data; 2) drafting the article and revising it critically for important intellectual content; and 3) final approval of the version to be published.

Anneli C. S. Bolund and Vivi Schlünssen are responsible for the overall content as guarantor(s). 


\section{REFERENCES}

1. Senthilselvan A, Dosman JA, Kirychuk SP, et al. Accelerated Lung Function Decline in Swine Confinement Workers. Chest. 1997;111(6):1733-41.

2. Iversen M, Dahl R. Working in swine-confinement buildings causes an accelerated decline in FEV1: a 7-yr follow-up of Danish farmers. Eur Respir J. 2000 Sep;16(3):404-8.

3. Eduard W, Pearce N, Douwes J. Chronic bronchitis, COPD, and lung function in farmers: the role of biological agents. Chest. 2009 Sep;136(3):716-25.

4. Thaon I, Thiebaut a, Jochault L, et al. Influence of hay and animal feed exposure on respiratory status: a longitudinal study. Eur Respir J. 2011 Apr;37(4):767-74.

5. Omland Ø. Exposure and respiratory health in farming in temperate zones - A review of the literature. Ann Agric Environ Med. 2002;9:119-36.

6. Sherrill DL, Lebowitz MD, Knudson RJ, et al. Continuous longitudinal regression equations for pulmonary function measures. Eur Respir J. 1992 Apr;5(4):452-62.

7. Cole TJ, Green PJ. Smoothing reference centile curves: the LMS method and penalized likelihood. Stat Med. 1992 Jul;11(10):1305-19.

8. Quanjer PH, Stanojevic S, Cole TJ, et al. Multi-ethnic reference values for spirometry for the 3-95-yr age range: the global lung function 2012 equations. Eur Respir J. 2012 Dec;40(6):1324-43.

9. Prior C, Falk M, Frank A. Longitudinal changes of sensitization to farming-related antigens among young farmers. Respiration. 2001 Jan;68(1):46-50.

10. Sunyer J, Zock JP, Kromhout H, et al. Lung function decline, chronic bronchitis, and occupational exposures in young adults. Am J Respir Crit Care Med. 2005 Nov 1;172(9):1139-45.

11. Elholm G, Omland O, Schlünssen, et al. The cohort of young Danish farmers - A longitudinal study of the health effects of farming exposure. Clin Epidemiol. 2010 Jan;2:45-50.

12. Committee on the etiology of chronic bronchitis. Definition and classification of chronic bronchitis for clinical and epidemiological purposes. The Lancet. 1965;(April 10):775-9.

13. Burney P, Jarvis D. The European Community Respiratory Health Survey II, ECRHS II Main Questionnaire. http://www.ecrhs.org/Quests/ECRHSIImainquestionnaire.pdf. Date last updated: September 25 2007. Date last accessed: May 12, 2015.

14. Miller MR, Hankinson J, Brusasco V, et al. Standardisation of spirometry. Eur Respir J. 2005 Aug;26(2):319-38.

15. Omland Ø, Sigsgaard T, Hjort C, et al. Lung status in young Danish rurals : the effect of farming exposure on asthma-like symptoms and lung function. Eur Respir J. 1999;13:31-7.

16. Yan K, Salome C, Woolcock AJ. Rapid method for measurement of bronchial responsiveness. Thorax. 1983 Oct;38(10):760-5.

17. James a, Ryan G. Testing airway responsiveness using inhaled methacholine or histamine. Respirology. 1997 Jun;2(2):97-105. 
18. Basinas I, Sigsgaard T, Heederik D, et al. Exposure to inhalable dust and endotoxin among Danish livestock farmers: results from the SUS cohort study. J Environ Monit. 2012 Feb;14(2):604-14.

19. Terho EO, Helenius H, Koskenvuo M. Childhood farm environment and asthma and sensitization in young adulthood. Allergy. 2002;57:1130-5.

20. Schulze a, van Strien RT, Praml G, et al. Characterisation of asthma among adults with and without childhood farm contact. Eur Respir J. 2007 Jun;29(6):1169-73.

21. Jacobsen G, Schlünssen V, Schaumburg I, Taudorf E, Sigsgaard T. Longitudinal lung function decline and wood dust exposure in the furniture industry. Eur Respir J. 2008 ;31(2):334-42.

22. Ware JH, Dockery DW, Louis TA, et al. Longitudinal and cross-sectional estimates of pulmonary function decline in never-smoking adults. Am J Epidemiol. 1990;132(4):685-700.

23. Van Pelt W, Borsboom GJ, Rijcken B, et al. Discrepancies between longitudinal and cross-sectional change in ventilatory function in 12 years of follow-up. Am J Respir Crit Care Med. 1994 May;149(5):1218-26.

24. Irwig L, Groeneveld H, Becklake M. Relationship of lung function loss to level of initial function: correcting for measurement error using the reliability coefficient. J Epidemiol Community Health. 1988;42(4):383-9.

25. Fletcher C, Peto R. The natural history of chronic airflow obstruction. Br Med J. 1977;1(June):16458.

26. Peto R. The horse-racing effect. Lancet. 1981;(August 29):467-8.

27. Halstensen AS, Heldal KK, Wouters IM, et al. Exposure to Grain Dust and Microbial Components in the Norwegian Grain and Compound Feed Industry. Ann Occup Hyg. 2013 Jun 28;1-10.

28. Basinas I, Sigsgaard T, Kromhout H, et al. A comprehensive review of levels and determinants of personal exposure to dust and endotoxin in livestock farming. J Expo Sci Environ Epidemiol. 2013 Nov 27;(October 2012):1-15.

29. Sigsgaard T, Hjort C, Omland Ø, et al. Respiratory health and allergy among young farmers and nonfarming rural males in Denmark: the SUS study. J agromedicine. 2004 Jan;9(2):223-38. 